www.jmscr.igmpublication.org

Impact Factor 3.79

Index Copernicus Value: 5.88

ISSN (e)-2347-176x ISSN (p) 2455-0450

crossref DOI: _http://dx.doi.org/10.18535/jmscr/v4i02.49

\title{
Effect of Stress on Mental Fitness in the Form of Reaction Time (Visual As Well As Auditory)
}

\author{
Author \\ Ranjan Kumar Dixit ${ }^{1}$, Trilok Ranjan Srivastav ${ }^{2}$, Monica Dixit ${ }^{3}$, Jai Prakash ${ }^{4}$ \\ Shahina Khan ${ }^{5}$ \\ ${ }^{1}$ Associate Professor (Physiology), Government Medical College, Kannauj, (UP) \\ ${ }^{2}$ Professor (Physiology), Government Medical College, Azamgarh, (UP) \\ ${ }^{3}$ Gorakhnath Hospital \\ 4,5 Demonstrator... Government Medical College, Kannauj \\ Email: ranjan_dixit1980@yahoo.co.in
}

\begin{abstract}
Back Ground And Aim: Medical students confront with significant academic, psychological, existential stressor throughout their professional training therefore this study is plan to see the effect of stress on mental fitness (reaction time visual and auditory).

Material and method: This study was done to assess the effects of stress on Mental fitness fitness in terms of visual and auditory reaction time in 60 young, healthy Medical students of age group17-22 yrs. In the groups, visual and auditory reaction time was measured at the beginning and after 6 month Results were analysed statistically by using student's t-test.

Result: After six months, there is no any significant change in visual and auditory reaction time in the group indicating no improved mental fitness.

Conclusion: There is no as such change in reaction time

Keyword: Visual and Auditory Reaction Time, Stress
\end{abstract}

\section{Introduction}

Medical students confront with significant academic, psychological, existential stressor throughout their professional training. Mental stress refers to changes in the psychophysiological state that people experience during the course of prolonged periods of demanding cognitive activity that require sustained mental efficiency ${ }^{[1]}$. Today's, it is becoming increasingly common for people to stretch their limits to squeeze more time for work. That extra time is usually taken by decreasing the time period for which we sleep. Though it seems as an easy concession to make, but slowly and surely this lack of sleep catches up with us ${ }^{[2]}$. Mental fitness includes or judge by reaction time. As reaction time is an indicator of the rate processing of sensory stimuli by central nervous system and its execution in form of response. This study is also aimed to asses, the stress can effect mental fitness (in the form of reaction time- visual and audibal3. 
Material and Method

\section{Selection of subject}

This study was conducted in dept of physiology between period Sept 2006 to April 2007. Control group consisted of age matched 60 students of medical college (30 boys and 30 girls). After routine medical check up written consent was taken from all the students.

\section{Inclusion criteria:}

1. Subjects in the age between 17-22 years.

2. Healthy Subject not suffering from any systemic illness

\section{Exclusion criteria:}

\section{Observations and Results}

Table 1: Age and Sex wise distribution of control group

\begin{tabular}{|l|l|l|l|}
\hline \multirow{2}{*}{ Age $($ Yrs $)$} & \multicolumn{2}{|l|}{ Sex } & Total \\
\cline { 2 - 3 } & Male & Female & \\
\hline $18-19$ & 9 & 17 & 26 \\
\hline $19-20$ & 21 & 13 & 34 \\
\hline Total & 30 & 30 & 60 \\
\hline
\end{tabular}

Table no. 1 shows age and sex wise distribution of control group. There were sixty students in control group, out of which thirty were males and thirty were females. Among them there were 9 males and 17 females between age range of 18-19 years and 21 males and 13 females between age ranges of 19-20 years.

Table 2: Comparison of Visual Reaction time (red and green) in control group (males) before and after six months

\begin{tabular}{|l|l|l|l|l|}
\hline \multirow{2}{*}{$\begin{array}{l}\text { VRT } \\
(\mathrm{m} \mathrm{sec})\end{array}$} & Before & After 6 months & t Value & P Value \\
\cline { 2 - 4 } Red light & Mean \pm SD $(\mathrm{n}=30)$ & Mean \pm SD $(\mathrm{n}=30)$ & & \\
\hline Green light & $234.93 \pm 15.68$ & $233.57 \pm 15.55$ & 2.22 & $>0.05$ \\
\hline
\end{tabular}

Table no.2 shows mean values of VRT for red and green in control group (males) before and after 6 months. It shows that there is no significant difference in VRT for red and green light values in control group (males) $(\mathrm{P}$ value $>0.05)$ before and after six months.

Table 3: Comparison of Visual Reaction time (red and green) in control group (females) before and after six months

\begin{tabular}{|l|l|l|l|l|}
\hline \multirow{2}{*}{$\begin{array}{l}\text { VRT } \\
(\mathrm{m} \mathrm{sec})\end{array}$} & Before & After 6 months & t Value & P Value \\
\cline { 2 - 4 } & Mean \pm SD $(\mathrm{n}=30)$ & Mean \pm SD $(\mathrm{n}=30)$ & & \\
\hline Red light & $237.33 \pm 6.98$ & $235.37 \pm 7.71$ & 1.07 & $>0.05$ \\
\hline Green light & $247.4 \pm 8.76$ & $246.2 \pm 6.87$ & 1.05 & $>0.05$ \\
\hline
\end{tabular}


Table no.3 shows mean values of VRT for red and green light in control group (females) before and after 6 months. It shows that there is no significant difference in VRT for red and green light values in control group (female) ( $\mathrm{P}$ value $>0.05$ ) before and after six months.

Table 4: Comparison of Auditory Reaction time (high pitch and low pitch sound) in control group (males) before and after six months

\begin{tabular}{|l|l|l|l|l|}
\hline $\begin{array}{l}\text { ART } \\
(\mathrm{m} \mathrm{sec})\end{array}$ & Before & After 6 months & t Value & P Value \\
\cline { 2 - 4 } $\begin{array}{l}\text { High pitch } \\
\text { sound(Tone) }\end{array}$ & $164.4 \pm 9.27$ & $163.5 \pm 9.59$ & 1.07 & $>0.05$ \\
\hline $\begin{array}{l}\text { Low pitch } \\
\text { sound(Click) }\end{array}$ & $173.17 \pm 7.22$ & $171.83 \pm 5.14$ & 1.78 & $>0.05$ \\
\hline
\end{tabular}

Table NO. 4 shows mean values of ART for high pitch and low pitch sound in control group (males) before and after 6 months. It shows that there is no significant difference between ART for high pitch and low pitch sound of control group (males) (P value $>0.05$ ) before and after six months.

Table 5: Comparison of Auditory Reaction time (high pitch and low pitch sound) in control group (females) before and after six months

\begin{tabular}{|l|l|l|l|l|}
\hline $\begin{array}{l}\text { ART } \\
(\mathrm{m} \mathrm{sec})\end{array}$ & Before & After 6 months & t Value & P Value \\
\cline { 2 - 3 } $\begin{array}{l}\text { High pitch } \\
\text { sound(Tone) }\end{array}$ & $164 \pm 5.83$ & $162.93 \pm 6.06$ & 1.76 & $>0.05$ \\
\hline $\begin{array}{l}\text { Low pitch } \\
\text { sound(Click) }\end{array}$ & $173.47 \pm 6.91$ & $171.9 \pm 4.57$ & 1.12 & $>0.05$ \\
\hline
\end{tabular}

Table NO. 5 shows mean values of ART for high pitch and low pitch sound in control group (females) before and after 6 months. It shows that there is no significant difference between ART for high pitch and low pitch sound of control group (females) (P value $>0.05$ ) before and after six months.

\section{Discussion}

Previous study said Stressed drivers adapted to high levels of demand fairly efficiently. The levels of stress involved here obviously fall within the range that can be compensated for by strain or mobilization. But, in contrast, Metzger and Parasuraman, (2001) found that, at higher levels of overload, created by a secondary task during driving in high traffic density and assessed by HR and self-report measures, performance does gradually but significantly decline. Parallel results were reported by Zeier (1994) for air traffic controllers.. Variation of stress level and performance with respect to time Task induced changes in stress are described within Matthews' system as patterned shifts in task engagement, distress, and worry. Patterns are sensitive to task and environmental demands. Matthews et al illustrated this effect with studies of automobile driving. Operators' appraisal of task demands (workload) and choice of coping strategy mediate these stress effects. Thus, for Matthews, stress is an adaptive transaction between operator and task. Matthews et al. speculate that the consequences of task automation will vary widely depending on appraisal of the reliability and ease of control of the system, type and number of residual tasks left to the operator, and interpersonal factors such as personality and coping style. Thus there is likely to be no simple remedy for stress-related problems associated with automation, such as boredom or complacency. Fine-grained assessment of the operator's feeling state and cognitions is required to determine vulnerability to performance degradation under stress. B. Performance or Behavioural Measures But the issue of which type of measure, self-report or neuro-physiological, is the better or more appropriate measure of stress 
effects is far from settled. Hancock and Vasmatzidis (1998) contend that, rather than either self-report or International Journal of Computer Trends and Technology physiological measures, task performance level should be the primary criterion for determining the effects of exposure to stress. They argue that change in behavioural performance efficiency is the most sensitive reflection of human response to stress, and that error-free performance is the principal criterion of work efficiency, especially in hightechnology systems. Therefore, continuing exposure to stress after work performance efficiency begins to fail, but before current physiological limits are reached, is inappropriate for both the safety and the productivity of the individual worker, their colleagues, and the systems within which they operate. Behavioural performance assessment should therefore supersede physiological assessment or self-report as the primary exposure criterion, although these other measures still provide important supplementary information There are, of course, others who disagree with this analysis, contending that how a person thinks and communicates about stress and/or how the body automatically reacts to stress are fundamental components of the stress syndrome that are not contained within measures of performance. Still, there have been several significant efforts, following the logic of Hancock and Vasmatzidis, which have been aimed at identifying and developing reliable performance measures to assess individual differences in reactivity to stress. Ackerman and Kanfer (1994) developed a battery of cognitive ability tests for predicting performance under stress. As a test bed, they used a dynamic Target/Threat Identification Task performed under time-pressure. Their final battery consisted of a mixture of cognitive and perceptual speed ability and stress-reactivity measures. They showed that these measures accounted for the major amount of individual differences in performance on a variety of complex tasks. Two tests, called The Dial Reading and Directional Headings Tests, were found to be particularly promising predictors of performance in stressful information processing activities.

Either The lack of research into the effect of the stress on sensory-motor fitness in terms of visual Auditory reaction time or Time duration is short like 6 month prompted that there was no change in sensory-motor fitness. It was found that stress in the form of regular study and exam held for medical students had no significant effect on sensory-motor fitness. The absence of any detoriation in sensory-motor fitness supports the conclusion that stress in the form study and regular exam are inappropriate methods for developing and maintaining sensory-motor fitness.

\section{Conclusion}

There is no as such changes in the mental fitness (visual and auditory reaction time) seen due to stress in our study.

\section{Financial support and sponsorship: nil Interest of conflict: no}

\section{References}

1. Kato, Y., Endo, H., Kizuka, T., 2009. Mental stress and impaired response processes:

2. Strohl, K., Merritt, P.S.L., Blatt, J., Pack, A.I., Council, Forrest, Rogus, Susan, Georges, Kate, Roth, Thomas, Kiley, James, Stutts, Jane, Kurrus, Roger, Waller, Pat, McCartt, Anne T., Willis, D., 1998. Drowsy Driving and Automobile Crashes. NHTSA, National Center on Sleep Disorders Research, National Heart, Lung, and Blood Institute.

3. Minal Patel, Singh SK. "Effect of pregnancy on visual reaction time Journal of Obstetric and Gynecology . 2006; Vol.56:410-412.

4. S. Triggs, T.J., Harris, W.G. (Eds.), 1982. Reaction Time of Drivers to Road Stimuli. Monash University, Victoria. p. 68.

5. Mathews, A. \& MacLeod, C. (2002) Induced processing biases have causal 
effects on anxiety. Cognition \& Emotion, 16, 331-354.

6. Matthews, G. (1996) Extraversion, emotion, and performance: A cognitive adaptive model. In G. Matthews (Ed.) Cognitive science perspectives on personality and emotion. Amsterdam: Elsevier.

7. Vasmatzidis,I., Schlegel, R. E., \& Hancock, P. A. (2002). An investigation of heat stress effects on time-sharing performance. Ergonomics. 45(3) 218-239

8. Ackerman, P. L, \& Kanfer, R. (1994) Improving problem-solving and decisionmaking skills under stress: Prediction and training (Final Report, Sep. 1991 - Jul. 1994). Report Number AD-A292104; REPT- 94-01

9. Matthews, G, Sparkes, T. J., \& Bygrave, H. M. (1996) Attentional overload, stress, and simulated driving performance. Human Performance, 9, 77-101. 